Accepted for publication the Journal of Curriculum Studies (29/06/20)

Visible and socially-just pedagogy: Implications for mathematics teacher education

Pete Wright

UCL Institute of Education

20 Bedford Way

London

United Kingdom

Email: pete.wright@ucl.ac.uk

ORCID iD: 0000-0002-6926-4237

Twitter: @petewrightioe

Word Count: 9199 


\title{
Visible and socially-just pedagogy: Implications for mathematics teacher education
}

\begin{abstract}
In this paper I consider the notion of "visible pedagogy" in refining a conceptualisation of "socially-just pedagogy" in the mathematics classroom. I explore reasons why the recent focus on promoting formative assessment and metacognition, embodied in Hattie's "visible learning", has failed to bring about the fundamental shift in pedagogic approaches that was hoped for. I draw on three sociocultural theories, Brousseau's "didactic contract", Bourdieu's theory of "reproduction" and Bernstein's theory of "pedagogic discourse", to explain the continued predominance of teacher-centred pedagogies in mathematics education. I highlight concerns raised by some equity-minded researchers that a "socially-just pedagogy", which incorporates collaborative, discursive, problemsolving and inquiry-oriented teaching approaches, might further disadvantage marginalised students due to its relative lack of structure. I argue for an alternative interpretation of Bernstein's "visible pedagogy" that rejects teachercentred approaches, as a way of making the instructional and regulative discourse more explicit, in favour of a "socially-just pedagogy" in which the teacher's "pedagogic rationale" is made more explicit to learners. I highlight the potential for such an approach, and exemplify what it might look like in practice, by drawing on my extensive experience as a teacher educator in analysing a vignette of typical classroom practice from sociocultural perspectives.
\end{abstract}

Keywords: Bernstein's theory of pedagogic discourse; Bourdieu's theory of reproduction; Brousseau's didactic contract; pedagogic rationale; socially-just pedagogy; visible pedagogy

\section{1) Introduction}

In this paper I consider the notion of "visible pedagogy" in refining a conceptualisation of "socially-just pedagogy" in the mathematics classroom. I highlight the extent to which "formative assessment" and "metacognition", embodied in Hattie's (2009) vision of "visible learning", have been influential in UK government policy initiatives targeted at teachers' professional development over the past two decades or more. It was anticipated that these initiatives would advance alternative teaching approaches which cultivate more autonomous learners, an essential element of a "socially-just pedagogy". However, I present evidence to suggest that such a fundamental shift in pedagogic approach has failed to materialise and that many students in mathematics classrooms continue to experience a largely disempowering curriculum. I contend that the largely cognitivist and constructivist theories, on which the advocates of formative assessment drew, are insufficient to explain the continued predominance of teacherled pedagogies. I draw on sociocultural theories, including Brousseau's "didactic contract", Bourdieu's theory of "reproduction" and Bernstein's theory of "pedagogic discourse", to provide greater insight into the status quo. I argue for an alternative approach to mathematics teacher education in which teachers are encouraged to engage with sociocultural perspectives and to share and discuss the reasons and thinking behind their pedagogic choices, i.e. their "pedagogic rationale", with their students. This is based on an alternative interpretation of Bernstein's (2000) notion of 
"visible pedagogy" that rejects teacher-centred approaches, as a way of making the "instructional" and "regulative discourse" more explicit, in favour of a "socially-just pedagogy" in which the teacher's pedagogic rationale is made more explicit to learners. I consider the potential of such an approach to help bring about the kind of fundamental pedagogic shift that those advocating formative assessment and metacognition had originally hoped for. Note that I am interpreting "pedagogy" in this paper to mean the method and practice of teaching.

I adopt a critical perspective in this paper which requires me to acknowledge the partiality of my position as researcher (Valero, 2004) and offer a certain degree of reflexivity, i.e. "the process of reflecting critically on the self as researcher" (Lincoln \& Guba, 2003, p. 283). A commitment towards equity and social justice has extensively shaped my thinking and practice as a secondary school mathematics teacher (15 years), curriculum developer ( 5 years), local authority consultant ( 2 years) and teacher educator/researcher ( 8 years and counting). I have developed and maintained an interest in what I describe as a "socially-just pedagogy", which focuses on promoting the engagement of all students and addressing the well-documented underachievement of many disadvantaged students in mathematics (Jorgensen, 2016), described further in Section 5. This pedagogy includes facilitating collaboration and discussion amongst students, adopting problem-solving and problem-posing approaches, promoting mathematical inquiries that develop learners' agency, and making mathematics more meaningful by relating it to students' own experiences and real-life situations. My doctoral studies (Wright, 2016; 2017) involved working collaboratively with a group of teacher researchers to translate theories around teaching mathematics for social justice into classroom practice. Two experiences, however, have challenged my thinking and moved my research interests in a slightly different direction.

The first experience was reading a paper by Lubienski (2004) which challenged my confidence in socially-just pedagogy as a means of promoting equity in mathematics teaching. Lubienski reports on the findings of a project exploring how seventh-grade students, in a socio-economically diverse school in the US, responded to a reformoriented curriculum that incorporated many aspects of a socially-just pedagogy. She found that students from less wealthy backgrounds were more prone to misinterpret the intentions of the teacher leading to lower levels of achievement than other students. The relatively unstructured nature of the teaching approaches appeared to further disadvantage already-marginalised students, whilst privileging middle-class students. Lubienski draws on Bernstein's (2000) notion of "invisible pedagogy" to argue that equity-minded educators should seek ways of helping all students appreciate teachers' intentions, by making their pedagogy more visible, so that they are in a better position to respond appropriately. She sees this as preferable to the alternative strategy of resorting to a more transmission-based, teacher-led curriculum, such as that which far too many mathematics learners, particularly those from disadvantaged backgrounds, experience in England (Foster, 2013; OFSTED, 2012).

The second experience was beginning to notice how often a teacher's pedagogical rationale was hidden from students and the negative impact this had on the development of mathematical understanding. In my role as tutor on an initial teacher education (ITE) programme, I regularly visit student teachers during their school 
placements to observe them teaching. The lesson observation is followed up with a one-to-one discussion in which we reflect in detail on the teaching approaches used and the learning outcomes of students. What began to strike me was how clearly most student teachers articulated their rationale for the pedagogical choices they made during the lesson, and yet students frequently misinterpreted their actions resulting in learning opportunities being lost. Reflecting on numerous observations of more experienced teachers in the past (as a head of department and local authority consultant), I believe this phenomenon is not unique to student teachers. However, the "disturbance" to my previous way of thinking (Mason, 2002), caused by the Lubienski article, awakened me to how "invisible pedagogy" is highly problematic in mathematics teaching. Hence my interest in making the rationale behind socially-just pedagogy more explicit to learners.

In order to ground my ideas in practice, I draw on my own experiences of the mathematics classroom to offer a vignette of teaching practices which are typical of those I have commonly observed in schools. In analysing this vignette, with reference to the three sociocultural theories, I exemplify what making the teacher's pedagogic rationale more explicit to learners might look like in practice. I conclude this paper by discussing the potential of this approach for bringing about a shift in pedagogic thinking among mathematics teachers and for advancing a "socially-just pedagogy" in the mathematics classroom.

\section{2) The limited impact of formative assessment and metacognition on dominant pedagogic approaches}

There is a dominant view of mathematics teaching in England, shared by many teachers, students, parents, and the general public, in which the teacher stands at the front of the class and "delivers" (a word that has grown in popularity recently) a lesson and students (often referred to as "pupils") sit in rows passively absorbing knowledge. Significant numbers of students in mathematics classrooms worldwide continue to experience a largely uninspiring curriculum, characterised by Skovsmose (2011) as the "exercise paradigm", in which the teacher typically demonstrates the application of a procedure to solve a closed problem. Students then complete a series of almost identical problems before being tested on their understanding. Limiting mathematical learning to memorising and practising procedures leads to the quiet disaffection of many students (Nardi \& Steward, 2003) and a general perception of the subject as "dull" and "irrelevant" (Grootenboer, 2013).

Mathematics educators have been calling for more than thirty years for more openended and discursive teaching approaches with a greater emphasis on promoting students' conceptual understanding and problem-solving skills (Cockcroft, 1982). Marshall and Drummond (2006) argue that "formative assessment" (often referred to in England as "Assessment for Learning") was originally seen as a "Trojan Horse" (p.134) for advancing an alternative pedagogic approach which cultivated more autonomous learners. Formative assessment was strongly endorsed by the National Strategy, a largescale programme between 1997 and 2011, aimed at bringing about significant changes in teaching approaches in England and attracting substantial resources from the UK government (Morgan, 2009). From my conversations with other 
teacher educators in my own and other universities, it is also firmly established as a core element of most ITE courses in England, endorsed by its prominence in the Department for Education's (2019) recent “Initial Teacher Training Core Content Framework".

Formative assessment is based on cognitivist and social constructivist notions of learning (drawing on Vygotsky and Dewey) in which teaching is seen as developing students' independence through their engagement in carefully-planned activities. Marshall and Drummond (2006) characterise formative assessment as involving teachers engaging in questioning, sharing success criteria with learners and providing feedback; and students engaging in peer and self-assessment. Black and Wiliam (1998) emphasise that self-assessment and effective feedback are essential components of formative assessment. For formative assessment to be meaningful, teaching activities need to provide opportunities for dialogue, with teachers posing rich questions, students reflecting on, and communicating, their evolving understanding and expressing their ideas.

A fundamental aim of formative assessment is to enable teachers to develop a greater awareness of individual students' progress and difficulties they encounter in their learning, which is then used to inform future teaching (Black \& Wiliam, 1998). Formative assessment is associated with "metacognition", which is generally accepted as entailing students' understanding of cognition and regulation of their own learning (Smith \& Mancy, 2018; Vorholter, 2019). Formative assessment and metacognition therefore involve developing greater awareness of the learning process amongst teachers and students respectively. Metacognition requires students to review their own mathematical knowledge, select approaches to use to solve problems, monitor and evaluate the success of methods they choose, and adapt their approaches accordingly (Hodgen, Foster, Marks, \& Brown, 2017). Metacognitive skills need time to acquire and need the teacher to model how to engage in productive discussions which involve students explaining their thinking and reasoning to the teacher and other students, and critiquing suggestions made by others. Recent research into metacognitive skills has focused on interactions required for students to solve problems in collaborative settings through sharing information and exchanging ideas with others (Smith \& Mancy, 2018; Vorholter, 2019). Hattie's (2009) notion of "visible learning" builds on notions of formative assessment, i.e. teachers constantly evaluate their own teaching based on its effect on students' learning, and metacognition, i.e. students become more aware of what they need to do to meet explicit learning goals.

There is strong evidence to suggest that formative assessment (particularly immediate verbal feedback focused on what students need to do to improve) and metacognition have a significant and positive impact on students' attainment and engagement, particularly for low-attaining students (Black \& Wiliam, 1998; Hattie, 2009; Hodgen, Foster, Marks, \& Brown, 2017; Smith \& Mancy, 2018; Vorholter, 2019). Bennett (2011), however, argues that these claims may be overstated and highlights the reliance of the original research findings, on which Black and Wiliam (1998) base their claims, on meta-analyses of a wide range of studies with varying definitions of formative assessment. He highlights how some people view formative assessment merely as an instrument or diagnostic test. Marshall and Drummond (2006) report how much of the practice they observed, which was claimed to be formative assessment, did not 
embrace what they saw as its underlying principle, i.e. to develop learners' autonomy, and involved little more than implementing techniques. Those teachers who embraced the "spirit" of formative assessment (about of fifth of those observed) tended to possess greater levels of agency enabling them to see past typical classroom constraints. Bennett (2011) describes formative assessment as a "work-in-progress" and highlights how its effectiveness can be undermined by teachers exhibiting bias towards particular groups of students or misinterpreting difficulties with language as demonstrating a lack of domain-specific understanding.

In summary, both formative assessment and metacognition have potential to significantly raise students' achievements in mathematics, particularly those of lowerattaining students, but only given the right conditions. These include the establishment of a learning environment which promotes collaboration and discussion amongst students, emphasises the importance of problem-solving skills, and recognises the need to foster the autonomy of learners. Unfortunately, as highlighted above, such conditions rarely exist in mathematics classrooms, which tend to be dominated by teacher-led pedagogies. Indeed, lower-attaining students, who potentially have most to gain from effective formative assessment and metacognition, are likely to experience a restricted curriculum based on transmissionist teaching approaches (Hodgen \& Marks, 2009; Morgan, 2009; Straehler-Pohl \& Gellert, 2013).

Given this situation, it is hardly surprising that attempts to implement formative assessment often lead to the adoption of techniques commonly associated with formative assessment, but without the fundamental shift in pedagogic approaches that it was originally intended to bring about. Morgan (2009) highlights how the National Strategy in England, which allocated a great deal of government resources towards promoting formative assessment practices including sharing learning objectives and asking "probing" questions, maintained a strong focus on teachercentred pedagogy and did little to develop student autonomy. A different mode of professional development is required if such a fundamental shift is to take place, i.e. one that encourages teachers to question commonly-held assumptions and beliefs about mathematics learning and helps them develop the agency they need to look beyond the constraints of the classroom. For this to happen, I argue that teacher educators need to draw more closely on sociocultural theories such as those presented in the next section.

\section{3) Sociocultural theories relating to visible and socially-just pedagogies}

In this section I draw on, and explain the choice of, three theories to generate an argument that making the teacher's pedagogic rationale more explicit to learners is an important element of a socially-just pedagogy: Brousseau's "didactic contract", Bourdieu's theory of "reproduction" and Bernstein's theory of "pedagogic discourse".

\section{1) Brousseau's "didactic contract"}

Brousseau (1997) formulated the notion of the "didactic contract" whilst observing students who experienced difficulties in learning mathematics. He refers to the "didactic contract" as the system of mostly implicit rules and mutual obligations which 
regulate the way that teachers and student behave towards each other in the passing on (or generation) of mathematical knowledge. The didactic contract becomes most obvious in situations where it breaks down and, in many mathematics classrooms, it can act as an impediment to the development of autonomous mathematics learners. The notion of the didactic contract helps make sense of why students often misinterpret the teachers' actions and why teacher-centred approaches to learning remain dominant in mathematics classrooms and resistant to attempts to change them.

Brousseau's view of learning as developing mathematical understanding from a "didactic situation", in contrast to the orthodox view of learning as gaining knowledge directly from the teacher, remains influential in French didactics (Chevallard, 2007). The didactic contract is shaped by experiences, with students developing mathematical beliefs, practices and habits-of-mind as a result of an often-tacit classroom culture. These, in turn, determine the socio-mathematical norms and the "rules of the game" within the mathematics classroom (Schoenfeld, 2012). Brousseau (1997) highlights the "didactic transposition" that occurs when mathematics is recontextualised as school mathematics, which is usually accompanied by a separation from its original meaning. The didactic contract existing in many classrooms tends to be focused on "answer-getting", rather than mathematical "sense-making". This encourages students to stop as soon as they obtain an answer, rather than looking for, or attempting to explain, underlying mathematical reasons (Schoenfeld, 2012).

Brousseau (1997) argues that orthodox didactic contracts, associated with answergetting, are difficult to modify and act as a constraint on students' mathematical learning. By laying down clearly the rules and conventions associated with school mathematics, the teacher limits the students' ability to control the didactic situation. This gives rise to "didactic tension", i.e. the more explicit the teacher is in the behaviour that she/he seeks, the more likely the student is to exhibit that behaviour without necessarily understanding the reason for doing so (Brousseau, 1984, cited in Mason, 2002). Brousseau (1997) describes how this can manifest itself in the classroom as students arriving at the correct solution by reading the didactical clues rather than by engaging with the mathematical problem. He highlights other ways in which the orthodox didactic contract can be problematic including its tendency to produce the "Topaze effect", whereby the teacher asks progressively easier questions until students are able to answer correctly, and the "Jourdain effect", whereby the teacher seeks to recognise something mathematically significant in a student's response to avoid the didactical situation being seen to have failed. Neither situation results in the student learning the mathematical knowledge that the teacher intended.

Schoenfeld (2012) argues for the establishment of an alternative didactic situation which is more conducive to engaging with rich mathematics, "sense-making" and developing deeper understanding. This should involve cultivating student agency and developing mathematical habits-of-mind that give students a sense of what mathematical tools are available and enable them to select and use appropriate tools to solve a given problem. This resonates with Brousseau's (1997) aim of establishing a didactic situation which lends itself to developing autonomous learners. However, given the dominance of teacher-centred pedagogy in mathematics classrooms, redefining the didactic contract to facilitate such a didactic situation is likely to prove 
challenging. Pepin (2014) highlights how students require support in bridging the gap between different didactic contracts when moving from one class to another. This is particularly acute when transitioning from school to university, where completely different socio-mathematical norms operate and which requires students to take greater responsibility for their own learning. She argues that such a move requires a "rupture" of the existing didactic contract so that a new contract can be established. I would suggest that a transformation of the didactic contract, from one based on orthodox views of teacher authority to one that facilitates student autonomy, requires a similar "rupture" to take place.

\section{2) Bourdieu's theory of "reproduction"}

Brousseau's didactic contract helps make sense of students misinterpreting teachers' actions in the mathematics classroom, however it does not explain why this phenomenon is more pronounced for students from less-wealthy backgrounds (Lubienski, 2004). Whilst Brousseau's analysis takes account of low-attaining students, it does not address issues related to socio-economic background. Pepin (2014) argues that attention should be given to students' willingness to identify with, as well as recognise, their obligations under the didactic contract, which is dependent on their upbringing and closely linked to Bourdieu's notions of social and cultural capital (Jorgensen, Gates, \& Roper, 2014). She argues that disadvantaged students are more likely than their more privileged peers to merely go along with (or even resist) their obligations under the didactic contract. Bourdieu's theory of "reproduction" (Bourdieu \& Passeron, 1990) is therefore useful in developing an argument that takes account of the socio-economic backgrounds of learners. Without addressing these issues, it is likely that implementing strategies for raising the mathematics achievement of lowattaining students, e.g. establishing an alternative pedagogic situation that promotes learner autonomy, will have even greater benefits for higher-attaining students, thus leading to a further widening of the attainment gap between the two groups.

Bourdieu argues that an inevitable function of schooling is to reproduce inequitable power relationships existing between various groups in society from generation to generation (Bourdieu \& Passeron, 1990). It achieves this by disguising how systemic advantage is afforded to children from dominant groups in society and by presenting itself as a genuine meritocracy in which those with natural ability are successful. In reality, schooling is far from a meritocracy, with some social and cultural resources, which tend to be acquired by children from middle-class families (through their upbringing), being assigned greater value and legitimacy than others (Jorgensen, Gates, \& Roper, 2014). These resources, which include languages and behaviours, are largely "symbolic". However, they result in middle-class students being more likely to identify as learners of mathematics and being better placed to take advantage of opportunities that present themselves in the mathematics classroom (Williams \& Choudhury, 2016).

Bourdieu argues that this "mathematical habitus", i.e. predisposition towards learning mathematics that aligns closely with the values of the school, exists solely for the purpose of enabling some students (mostly from privileged backgrounds) to succeed at the expense of others. Attempting to address inequity by helping some disadvantaged students realign their habitus with those values recognised by the school, merely 
enables them to join the privileged group in exploiting others, and serves to reinforce the myth that school is a genuine meritocracy (Bourdieu \& Passeron, 1990). In "going beyond Bourdieu", Williams and Choudhury (2016) claim mathematics has more to offer learners than merely the "exchange value" associated with mathematics qualifications, which regulates access to higher-paid employment (Black, Mendick, \& Solomon, 2009). They highlight the "use value" of mathematics, which includes the potential to apply mathematical knowledge to model and solve real-life problems. They draw on Bourdieu's notion of "reflexive sociology" to argue that the focus for equity-minded educators should be on drawing attention to the "use value" of mathematics, whilst exposing the arbitrary nature of its "exchange value". This can be done by revealing and challenging common myths that disguise the arbitrary nature of "symbolic capital", e.g. that mathematical success is attributable to natural ability, or that the mathematics classroom offers equal opportunities to all students. By opening up to scrutiny what it means to be a successful learner, teachers can expose and ultimately undermine the exploitative nature of school mathematics (Williams \& Choudhury, 2016).

In relating Bourdieu's reflexive sociology to Brousseau's didactic contract, I argue that, to bring about a transformation of the didactic contract, it is necessary for the teacher to make explicit the desirability of student autonomy, and how it relates to the "use value" of mathematics. Attention needs to be drawn to the arbitrary nature of mathematical beliefs, practices and habits-of-mind that lead students (and teachers) to focus on "answer-getting". Teachers need to share their pedagogic rationale with students, e.g. by explaining their reasons for providing rich experiences in the classroom that are conducive to mathematical "sense-making" and fostering deeper understanding.

\section{3) Bernstein's theory of "pedagogic discourse"}

Lubienski, whose 2004 paper alerted me to the highly problematic nature of invisible pedagogy, draws heavily on Bernstein's (2000) theory of "pedagogic discourse".

Bernstein shares with Bourdieu a concern for socio-economic dimensions that affect students' success in the mathematics classroom, indeed he draws heavily on Bourdieu's ideas in his analysis. In common with Brousseau, he explores the relationship between invisible pedagogy and the implicit "rules of the game" within the classroom. He contends that children from more disadvantaged backgrounds are generally less able than others to decipher the "rules of the game" which need to be followed in order to achieve success in mathematics. These include the "recognition rules", i.e. being able to identify the correct meaning from classroom tasks (as intended by the teacher), and "realisation rules", i.e. being able to formulate a legitimate response. Bernstein's theory of "pedagogic discourse" is therefore particularly useful for developing an argument that addresses the issues raised in Lubienski's (2004) paper.

Bernstein (2000) distinguishes between two aspects of pedagogical discourse: the "regulative discourse" relating to rules governing the maintenance of social order; and the "instructional discourse" relating to rules governing the discursive order. He argues that the regulative discourse is always dominant over the instructional discourse. In teacher-led pedagogies, which he refers to as "performance models" and describes as 
dominating all levels of school education in England, the instructional discourse and the regulative discourse are generally explicit, hence the pedagogy tends to be "visible". In contrast, the instructional discourse and regulative discourse tend to be implicit within "competence models" of teaching, hence the pedagogy is generally "invisible". Competence models of teaching include approaches which focus on developing autonomous learners ("cognitive empowerment" in Bernstein's terms), resonating with Brousseau's vision of a didactic situation, and my initial conceptualisation of a "socially-just pedagogy". Therefore, the difficulty faced by disadvantaged students in deciphering the rules of the game is likely to be further compounded in classrooms where such pedagogies are employed as these rules tend to be less visible, explaining Lubienski's (2004) findings.

Bernstein's (2000) theory of "pedagogic discourse" suggests an argument for making mathematics pedagogy more visible to learners should include seeking to make the rules of the game that regulate success more explicit to students. One way of achieving this would be to adopt more teacher-centred approaches, which Bernstein would characterise as "visible". What I am arguing here is that, instead of accepting the "invisible" nature of a (competence-based) socially-just pedagogy as inevitable, equityminded researchers should seek ways of making the instructional and regulative discourses of such a pedagogy more "visible". Bernstein contends that a socially-just pedagogy requires teachers to cultivate "relational authority", i.e. negotiating the rules of the classroom with students and explaining the reasons behind pedagogical choices, rather than relying on "positional authority", i.e. teachers appealing to their position of power in imposing rules.

In summary, a consideration of the three sociocultural theories in this section suggests refining my initial conceptualisation of socially-just pedagogy by seeking ways to make the teacher's pedagogic rationale more explicit to learners. This might be through: challenging existing socio-mathematical norms and seeking to establish an alternative classroom climate focusing on mathematical sense-making; challenging common myths relating to school mathematics and opening up to scrutiny what it means to be a successful learner; sharing and negotiating classroom rules (both pedagogical and mathematical) with students and making the reasons behind these clear and transparent, in order to promote mutual understanding and respect. In the next section I exemplify what this might look like in practice by analysing a vignette of typical mathematics teaching.

\section{4) Making the teacher's pedagogic rationale explicit to learners}

I offer below a vignette of teaching practices which are typical of those which I commonly come across in schools. It is based mostly on my observation of a lesson taught by a student teacher nearing the end of his qualifying year, who I have named "Adi", and our post-lesson reflective discussion. The lesson was taught to a lowattaining class (grouping by prior attainment is common in schools in England) of Year 8 (ages 12-13) students, located in a non-selective school in a relatively deprived area of London. I have supplemented the account of Adi's lesson with examples of practice from other lessons taught by different student teachers to similar students in comparable schools. These have been adapted to the context of Adi's lesson to 
provide a coherent narrative. Since the vignette is offered for illustrative purposes only, and to facilitate an analysis of typical mathematical classroom practices with reference to the sociocultural theories, I have not felt it necessary to distinguish between practice originating from Adi's lesson and that from other lessons.

\section{1) A vignette of typical classroom practice}

To facilitate the analysis, I have broken the vignette down into four phases. In each phase the "description" is informed by notes from lesson observations and the "commentary" is informed by notes from post-lesson reflective discussions. Note that, in the dialogue, S1, S2, S3, etc. refer to different students.

\section{Phase 1: Description}

Students' arrival for the lesson is spread over a period of 2 to 3 minutes. Adi greets students individually as they arrive and directs them towards an activity already displayed on the screen (via a projector connected to his laptop). Students are asked to calculate the area of five shapes (see figure 1 below).

1)

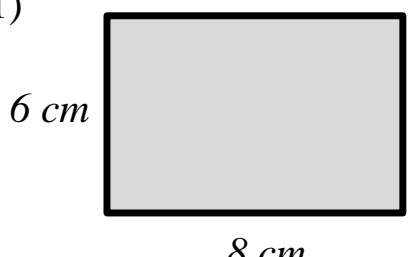

$8 \mathrm{~cm}$

4)

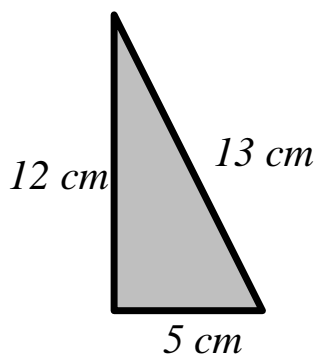

2)

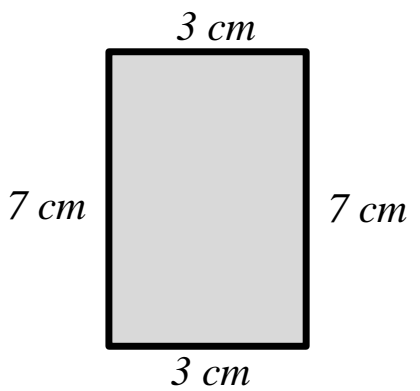

3)

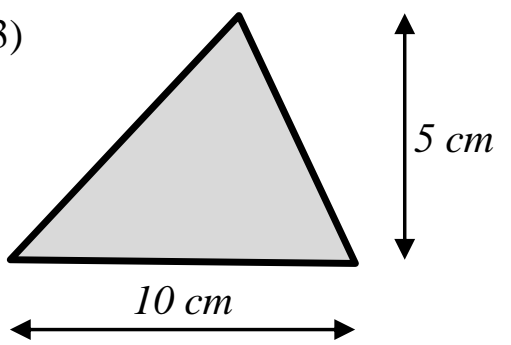

5)

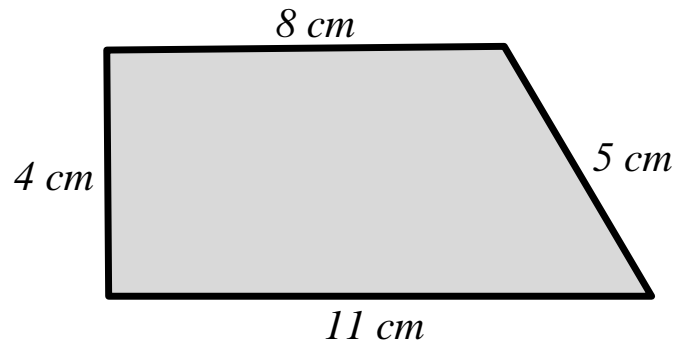

Figure 1. Initial five shapes

An additional question is also written on the board: "Extension: How many different rectangles can you find with an area of $24 \mathrm{~cm}^{2}$ ?"

It appears most students have arrived. Adi sets a timer (displayed on the screen) which counts down from 10 minutes.

Adi: Remember I want you to find the area of each shape. You've got 10 minutes.

Do it on your own, please!

St1: Do we need to copy the diagrams?

Adi: Yes, otherwise you won't remember what the questions were.

Another student arrives. Adi tells her: "You're late" and writes her name on the board. 


\section{Phase 1: Commentary}

Adi explains that students are coming from different parts of the school. The department policy is therefore to have a "settler" task displayed on the board as they arrive.

The timer is to encourage students to remain focused and to maintain "pace" (i.e. not spending too long on one task).

Adi has thought carefully about his choice of shapes. He judges most students will be confident with rectangles and triangles, but some will struggle with the trapezium as they have only recently been introduced to the formula. He thinks some students might confuse area with perimeter, so he deliberately includes some dimensions that are not needed (in shapes $2,4,5$ ) to see if this is the case. The "Extension" activity is to provide differentiation and is targeted at students who complete the initial questions within the 10 minutes.

Students are expected to arrive within 5 minutes of the official start of the lesson and can expect a warning if they are late. This is written in the school behaviour policy which they have in their planners.

\section{Phase 2: Description}

Students begin work and Adi circulates, scanning students' books, encouraging some students to engage with the task and offering advice to students who are stuck on a question. After a few minutes he stops the class briefly to talk to them.

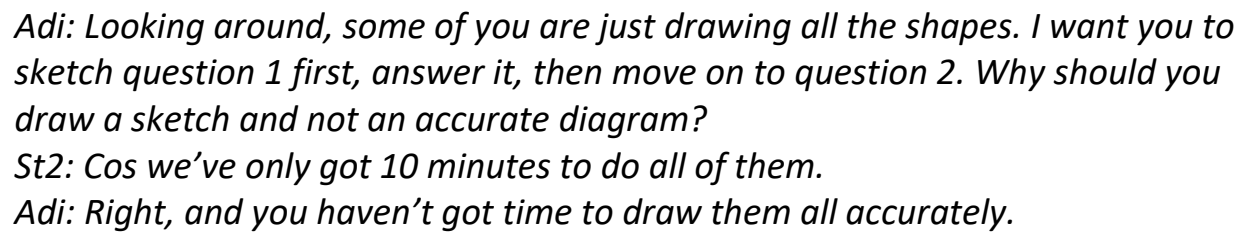

Students continue to work on the problems. Student 3 finishes the initial questions before the 10 minutes are up and calls out: "Sir, I've finished".

Adi comes over and checks the answers, which are all correct. He ticks them and says: "Well done, perfect! Have a go at the extension."

\section{Phase 2: Commentary}

Whilst circulating, Adi notices that several students are trying to copy all five diagrams accurately before calculating the areas. He is concerned they will not have time to complete any of the questions.

\section{Phase 3: Description}

When the 10 minutes are up, Adi draws a sketch of the triangle in question 3 on the board and, next to this, sketches a rectangle with the same base and height (see figure 2 below). He asks the class to listen. 

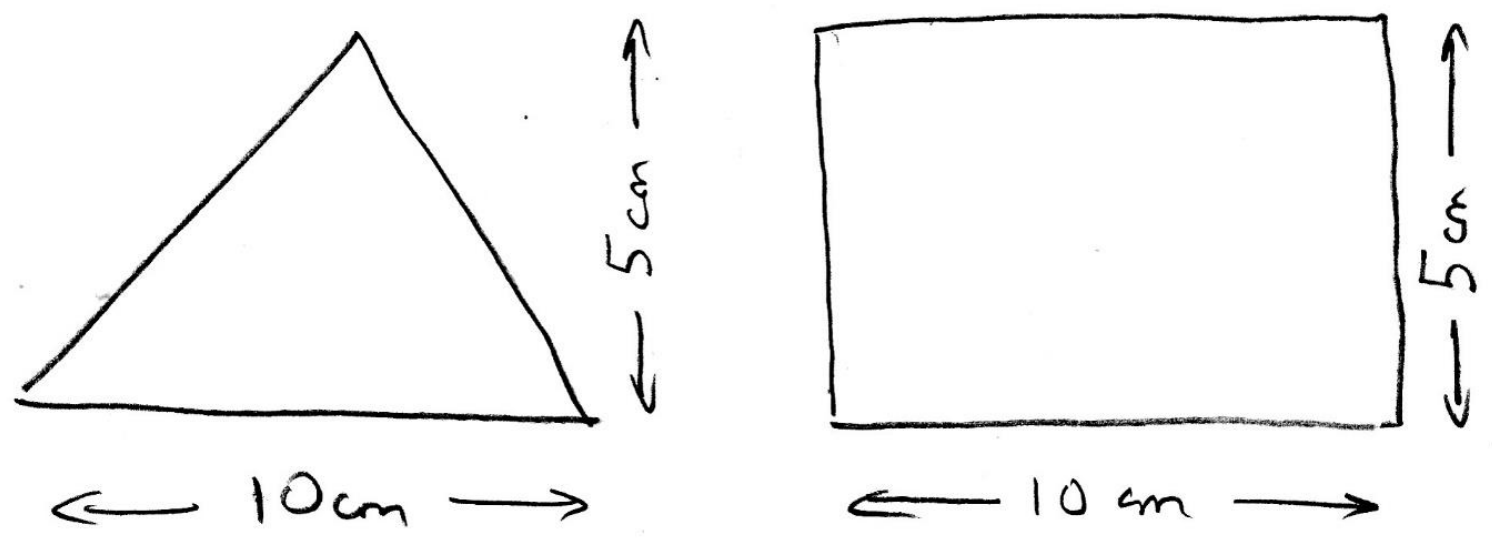

Figure 2: Two comparable shapes

Adi: Some of you have put 50 for question 3. [pointing to the triangle] What's the area of this shape? [pointing to the rectangle]

St4: Fifty [Adi writes $50 \mathrm{~cm}^{2}$ under the rectangle].

Adi: [question directed at Student 5] Can these two shapes have the same area?

St5: It's twenty-five.

Adi: What's twenty-five?

St5: The triangle, it's twenty-five.

Adi: Yes, but why can't both shapes be fifty?

St5: You have to halve it.

Adi: Well done, you're right but why can't both shapes have the same area?

St5: One's a rectangle and one's a triangle.

Adi: [question directed towards other students] Someone else, why can't these two shapes have the same area? ... [no response] ... OK, what do the two shapes have in common? ... [no response] ... What's the base of this shape? [pointing to the rectangle]

St6: Ten.

Adi: Good. What's the base of this shape? [pointing to the rectangle]

St6: Ten.

Adi: Well done, so they've got the same base. Have they both got the same height?

St6: Yes.

Adi: So why can't they have the same area?

St6: Dunno!

Adi: [question directed at Student 5]: So how did you use the base and height to get twenty-five?

St5: I did base times height and half of it

Adi: Excellent, copy this into your books, you're going to need it later. [he writes

"Area of triangle $=1 / 2 \times$ base $\times$ height" on the board]

\section{Phase 3: Commentary}

Adi notices that several students make the same error with question 3, i.e. multiplying the base and height, but omitting to divide by 2 . His questioning is aimed at getting students to recognise for themselves that the two shapes cannot have the same area, as the triangle fits inside the rectangle. Eventually he gives up and resorts to asking Student 5 to explain how he got the correct answer. 


\section{Phase 4: Description}

Adi gives the following instructions to the whole class: "Work in pairs with the person sitting next to you. See if you can find the area of the trapezium [shape 5] in more than one way. You could use the formula for the area of the trapezium, or you could use what you already know about areas of rectangles and triangles."

Adi writes "Area of trapezium $=1 / 2 \times(a+b) \times h$ " on the board.

Students engage with the task and discuss their ideas enthusiastically with their partners.

After a while, Adi approaches one pair who appear to have finished.
Adi: What did you get?
St7: Thirty-eight.
Adi: Excellent, talk me through how you got that.
Adi: Why did you put 4 and not 5 for $h$ ?
St7: $\operatorname{Cos} h$ is 4.
Adi: What does $h$ stand for in the formula?
St8: Height. sketch]
St8: Cos it's not right-angles. from bottom left to top right]. right].
Adi: Anything difficult about this method?
Adi: Why?
St8: Cos the base is 8 .
Adi: OK. Which method do you think is best?
St7: The formula.
Adi: Why?
St7: It's quicker.

St7: We used the formula and put $a$ as $8, b$ as 11 , and $h$ as 4 .

Adi: Why can't the height be 5? [pointing to the side with length 5 in the pair's

Adi: OK, good. Talk me through this other method [pointing at a diagonal drawn

St7: We did half times 8 times 4 for this triangle [pointing to the triangle on the left] and half times 11 times 4 for this triangle [pointing to the triangle on the

St8: We had to turn this one upside down [pointing to the triangle on the left].

\section{Phase 4: Commentary}

Adi notices that very few students attempted question 5 . He decides to allocate more time to discuss this question.

\section{2) Analysis of typical classroom practice}

The following analysis aims to exemplify what making the teacher's pedagogical rationale explicit to learners might look like in practice and is broken down into four subsections. Each subsection provides an analysis from a different theoretical perspective. The first subsection draws on cognitivist and constructivist frameworks, including those relating to formative assessment and metacognition discussed in Section 2, which are routinely addressed during university-based sessions as part of the ITE programme (e.g. Black \& William, 1998). The analysis is therefore likely to closely resemble many post-lesson reflective discussions that take place between 
student teachers and their tutors. The next three subsections draw on the three sociocultural frameworks discussed in Section 3. The most significant elements of the frameworks used in the analysis are shown in Table 1 below. Since these frameworks are not routinely addressed in depth during the ITE programme, the analysis is likely to differ substantially from most post-lesson reflective discussions.

The following questions are addressed in each analysis:

- How can theory provide insight into why students misinterpret the teacher's actions?

- What might a teacher do differently to make their pedagogic rationale more explicit to learners?

- How might a teacher educator support the teacher in doing this?

\begin{tabular}{|c|c|c|}
\hline $\begin{array}{l}\text { Brousseau's "didactic } \\
\text { contract" }\end{array}$ & $\begin{array}{l}\text { Bourdieu's theory of } \\
\text { "reproduction" }\end{array}$ & $\begin{array}{l}\text { Bernstein's theory of } \\
\text { "pedagogic discourse" }\end{array}$ \\
\hline $\begin{array}{l}\text { "Socio-mathematical } \\
\text { norms" - derived from } \\
\text { tacit classroom culture. } \\
\text { "Didactic contract" - } \\
\text { "answer-getting" rather } \\
\text { than mathematical } \\
\text { "meaning making". } \\
\text { "Didactic tension" - } \\
\text { "Topaze Effect" and } \\
\text { "Jourdain Effect". } \\
\text { "Didactic situation" - } \\
\text { student agency and } \\
\text { mathematical habits-of- } \\
\text { mind. }\end{array}$ & $\begin{array}{l}\text { School mathematics } \\
\text { falsely presented as a } \\
\text { meritocracy. } \\
\text { "Social" and "cultural } \\
\text { capital" - some resources } \\
\text { assigned greater value by } \\
\text { school. } \\
\text { Middle-class students } \\
\text { more likely to identify as } \\
\text { mathematics learners. } \\
\text { "Reflexive sociology" - } \\
\text { emphasise "use value" } \\
\text { and expose arbitrary } \\
\text { nature of "exchange } \\
\text { value". }\end{array}$ & $\begin{array}{l}\text { "Rules of the game" - } \\
\text { "recognition rules" and } \\
\text { "realisation rules". } \\
\text { "Visible" (teacher-led) and } \\
\text { "invisible pedagogy" } \\
\text { (competence models). } \\
\text { "Regulative discourse" } \\
\text { dominant over } \\
\text { "instructional discourse". } \\
\text { "Relational" and } \\
\text { "positional authority". }\end{array}$ \\
\hline
\end{tabular}

Table 1: Elements of sociocultural frameworks used in the analysis

\subsection{1) Analysis drawing on cognitivist/constructivist frameworks:}

There are several examples in the vignette that illustrate the common use of formative assessment and metacognition in mathematics teaching. For example, Adi asks a range of probing questions to encourage students to explain their reasoning including, in Phase 2, why it is desirable to draw a sketch rather than an accurate diagram. This question is prompted by him noticing, whilst circulating the class, that some students have misinterpreted his instructions (in Phase 1) to draw a sketch, believing that they need to copy the diagrams accurately. Whilst Student 2's response is valid, it focuses on time constraints, and ignores the potential value of sketches in shifting attention onto the properties of the shapes. Theories around metacognition suggest Adi might 
develop further his use of success criteria with students. He might be supported in doing so by encouraging him to reflect in detail on why a sketch is more desirable in this case and what questions he might ask students to help them to appreciate not only what the success criteria are (drawing a sketch), but also how these will help them learn (by focusing on mathematical properties).

There are several opportunities provided in the vignette for students to discuss their work and communicate their reasoning, e.g. in Phase 4, two students (working as a pair) are encouraged by Adi to explain their methods and evaluate which method was most effective in answering the question. However, other opportunities to encourage further discussion are missed, such as the redundant measurements deliberately included in some shapes used in Phase 1, which could be used to draw out possible confusion between area and perimeter. Adi might look for ways of using rich questioning to elicit students' understanding of key mathematical concepts, e.g. by asking: "Was there anything confusing about calculating the area of Shape 2 ?" He might be supported in doing so by asking him to consider other instances where he uses students' errors as learning opportunities, e.g. in Phase 3, where he makes use of a common error (some students wrote " 50 " for the answer to question 3 ) to prompt a whole-class discussion. It would be helpful to refer Adi back to theoretical frameworks relating to drawing out misconceptions through rich questioning (e.g. Swan, 2006) routinely discussed during university-based sessions.

\subsection{2) Analysis drawing on Brousseau's "didactic contract":}

There are several instances of practice in the vignette which suggest the existence of socio-mathematical norms, characteristic of an orthodox "answer-getting" didactic contract, which appear to be reinforced by tacit classroom culture. These include Adi's use of a timer in Phase 1, which implies that value is assigned to working quickly, and the praise he offers, in Phase 2, to Student 3 for attaining the correct answers. The students' acceptance of this didactic contract is illustrated, in Phase 4, by Student 7's justification of the "formula method" as being better because it is quicker. Pepin (2014) suggests that a "rupture" of the orthodox didactic contract is required in order to establish an alternative didactic contract based on mathematical "meaning making". Adi might achieve this by questioning statements or responses students make which indicate socio-mathematical norms that need to be challenged, e.g. by asking "Is the quickest method always the best?" However, before he can do so, Adi needs to develop a greater awareness of the tacit culture in his classroom and how his own actions may contribute towards either reinforcing or challenging this culture. In supporting him with this, it may be necessary to act as a critical friend in confronting him with some of the messages implicit in the pedagogical actions he takes and asking him to consider what he might do to foster a classroom culture that supports an alternative didactic situation. An example of the latter might be, in Phase 4, to deliberately and publicly praise Students 7 and 8 for engaging with and explaining multiple methods, rather than focusing praise on correct answers. For example, he might say: "Excellent, you've managed to find two different methods on your own and you've explained to me why one is best".

In Phase 3, Adi attempts to help students see for themselves why the answer " 50 " cannot be correct for both shapes by comparing a rectangle and triangle with the same 
base and height. However, he struggles to achieve this. Student 5 seems to misread Adi's question about whether the two shapes can have the same area and proffers instead a justification for the correct answer, providing further evidence of the existence of an "answer-getting" didactic contract. Adi progressively simplifies the questions he asks until he finds one that a student can answer, i.e. "What's the base of this shape?" (an example of the "Topaze effect"). He finally abandons his efforts at cultivating students' autonomy when he acknowledges the mathematical significance of Student 5's response (an example of the "Jourdain effect"). It is perfectly understandable that Adi does not wish to challenge Student 5's responses, given that he is volunteering a mathematically correct argument, however, in not doing so, he may be reinforcing the didactic tension which is apparent. This highlights how bringing about a rupture in the didactic contract may prove to be an uncomfortable process for any teacher and one which requires the support of a critical friend. Familiarity with the notion of Brousseau's didactic contract appears to be an essential pre-requisite for a teacher in taking on such a formidable challenge.

\subsection{3) Analysis drawing on Bourdieu's theory of "reproduction":}

There are examples of common practice in the vignette which appear to be based on assumptions (claimed by Bourdieu to be false) that school mathematics provides a level playing field. For example, in Phase 1, Adi provides an extension task which involves exploring how many different rectangles can be found with an area of $24 \mathrm{~cm}^{2}$. In contrast to the other tasks in Phase 1, this more open-ended task offers an opportunity for students to develop mathematical agency in making decisions relating to the direction they will take and which procedures to apply in solving a problem.

Such agency is essential for applying mathematics to solving problems encountered in real life, in other words, it relates more closely to the "use value" of mathematics, whereas other tasks that encourage "answer-getting" (see previous section) are more closely related to its "exchange value". It also offers a potentially more engaging mathematical task that may encourage a wider range of students to identify themselves as mathematics learners. Limiting opportunities to develop mathematical agency to higher attaining students (in this case those that complete the initial tasks quickly) might be seen as reinforcing differential access to learning opportunities. Adi should be encouraged to consider the extent to which all students are able to access mathematically rich tasks. This should be related to Bourdieu's notions of "social" and "cultural capital", the privileged position occupied by those students who possess them, and how this increases the likelihood that middle-class children will identify themselves as mathematics learners.

There are other examples of pedagogical actions taken in the vignette that may be seen as leading to the alienation of some students. For example, in Phase 1 , despite the inclusion of potentially rich tasks that might prompt valuable discussion, students are asked to work on their own. Adi should be encouraged to reflect on these actions, e.g. consider carefully whether students really need 10 minutes to work on their own in order to settle (perhaps a minute or two would be sufficient, allowing more time for discussion). Challenging socio-mathematical norms that are associated with "answergetting" (see previous subsection) can be considered as analogous to exposing the arbitrary nature of the "exchange value" of school mathematics. Similarly promoting norms associated with "meaning-making" can be seen as analogous to emphasising its 
"use value". This might also be achieved by making explicit to students how mathematical processes might be applied in solving real-life problems, e.g. in Phase 2, Adi might consider posing a series of real-life scenarios and asking students whether in each case it would be more appropriate to draw a sketch or an accurate diagram to help in solving them.

\subsection{4) Analysis drawing on Bernstein's theory of "pedagogic discourse":}

There are several examples of practice in the vignette in which attempts are made to engage students in mathematical "meaning making", but they are unable to formulate legitimate responses, i.e. realise success, due to misinterpreting the teacher's actions. This highlights how students often fail to decipher the "rules of the game" by recognising the mathematical meaning of the tasks presented by the teacher. This problem is exemplified, in Phase 3, when Adi asks students whether the triangle and rectangle can have the same area (see the "didactic contract" subsection above). Rather than simplifying his questions to avoid students misinterpreting them, he might explain: "What I'm trying to do here is help you see for yourselves why the answer 50 cannot be correct". In doing so he would be sharing his pedagogic rationale with students in order to make his pedagogy more visible. This might appear to be moving away from collaborative and discursive pedagogies towards more teacher-centred instruction, in which case he may prefer to pose questions to prompt a discussion with students around the reasons for his choice of pedagogic approach. In the above example he might ask students: "Why do you think I picked these two shapes?" Similarly, in Phase 4, he might prompt a discussion around his pedagogic rationale by asking questions such as: "Why do you think I asked you to work in pairs? Why do you think I asked you to find the area in more than one way? Why do you think I gave you the dimensions of all four sides when not all were needed?" If he wanted to facilitate a group discussion around his pedagogic rationale, he might provide statements for students to match with such questions. In this case, the statements might include: "To encourage us to share ideas with each other; To help us appreciate there might be several ways of solving a problem; To help us identify the key information in a question."

Adi shows evidence of appreciating the importance of building relationships of mutual trust and support, e.g. in Phase 1, he greets students as they arrive. Bernstein highlights how the "regulative discourse" is always dominant over the "instructional discourse" and hence Adi might seek ways of making his "regulative discourse" more visible by employing "relational authority", rather than "positional authority", to regulate students' behaviour. This might be achieved, in Phase 1 , by explaining to a student who arrives late how this might disrupt her own learning and that of others, rather than simply appealing to the authority of the school's behaviour policy in rebuking her. If Adi felt it was justified for students to work for some time on their own in Phase 2 (to help them settle) then this reason might be explained clearly to students. In supporting Adi's development of "relational authority", he might be encouraged to appreciate its value by seeking feedback from students after the lesson on how they felt about him explaining his reasons for seeking compliance with classroom expectations. 


\section{5) Discussion: Implications for mathematics teacher education}

In this section, I consider the need for a socially-just pedagogy and the implications of the argument presented in this paper for what it might look like. The strong and persistent association between children's socio-economic background and their achievement, particularly in mathematics (Boaler, Altendorf, \& Kent, 2011), is an indicator of the high levels of inequity which exist within the current schooling system. Whilst other disparities in mathematical achievement and participation remain, e.g. between boys/girls and different ethnic groups, socio-economic disadvantage remains the most decisive factor in determining a student's success in school mathematics (Jorgensen, 2016). Since mathematics qualifications regulate access to higher-status university courses and better-paid employment (Black, Mendick, \& Solomon, 2009), under-achievement restricts the social mobility of students from less-wealthy backgrounds, thus reproducing patterns of inequality in society between successive generations. An equitable and socially-just curriculum would be one in which a child's capacity to succeed in school is not pre-determined by her/his socio-economic background, sex, gender, ethnicity, sexuality, religious beliefs, cultural heritage, geographical location, choice or allocation of school, etc. Cotton (2013, p. 74) describes a socially-just mathematics education as one in which "you would be happy for a child you love to learn in any classroom in any school, and to exchange places with any child in any classroom in any school".

In my doctoral studies, I employed a conceptualisation of "teaching mathematics for social justice" (Wright, 2016; 2017) which included what I refer to in this paper as a "socially-just pedagogy". This pedagogy draws on the ideas of Gutstein (2006), who argues that a teaching approach emphasising communication, reasoning and problem solving, which enables learners to acquire "mathematical power" (i.e. the confidence to solve complex mathematical tasks), is a necessary component of a genuinely empowering mathematics curriculum. It also draws on the ideas of Skovsmose (2011), who stresses the importance of students engaging in investigations, in which they pose their own questions and decide which directions to take, for developing mathematical agency. A socially-just pedagogy is therefore characterised by collaborative and discursive teaching approaches which encourage students to share and discuss different methods for finding solutions to open-ended problem-solving tasks. It promotes communication, reasoning and critical thinking, and embraces errors as learning opportunities.

The benefits of such a socially-just mathematics pedagogy, include increased levels of engagement, enjoyment and fulfilment amongst students (Hudson, 2018; Wright, 2016; 2017) and higher levels of conceptual understanding (Foster, 2018; Skemp, 1972; Swan, 2006). It can also lead to more students, particularly those from disadvantaged backgrounds, displaying positive attitudes towards mathematics and experiencing success, including achieving highly in traditional forms of assessment (Boaler, 1998; 2008; Smith, Lee, \& Newmann, 2001). These benefits are similar in nature to those claimed more generally for formative assessment and metacognition. Indeed, as highlighted in Section 2, the fundamental shift in pedagogic approaches anticipated by those advocating these strategies, particularly the development of learners' autonomy, resonates with calls for a socially-just pedagogy. However, the implementation of formative assessment and metacognition has done little to 
empower mathematics learners or challenge the teacher-led pedagogy which dominates most mathematics classrooms (see evidence presented at the beginning of Section 2). To understand why, it is necessary to draw on sociocultural theories such as those discussed in Section 3, which help to explain the resistance of the didactic contract to change (Brousseau, 1997), the role school plays in reproducing inequities in society from generation to generation (Bourdieu \& Passeron, 1990) and the implicit nature of the rules of the game that govern which students achieve success (Bernstein, 2000).

Williams and Choudhury (2016) highlight the damaging effects of 'transmissionist' (i.e. teacher-centred) pedagogies, which are associated with increasing levels of student disengagement from mathematics over the course of their schooling and with students choosing not to study mathematics beyond the compulsory level. Worryingly, some teacher-centred pedagogies, such as "direct instruction" and "explicit instruction", have experienced a recent resurgence in popularity. Whilst advocates of direct and explicit instruction claim these approaches offer more than just the transmission of knowledge, Ewing (2011) highlights how they present similar problems in relation to the disengagement, alienation and disempowerment of learners, particularly those from disadvantaged backgrounds. Ironically, they are often justified with reference to notions of equity, with similar concerns raised about working-class students' tendencies to misinterpret the teachers' actions when employing less-structured pedagogies as those identified by Lubienski (2004). However, the case for teachercentred pedagogies, in which the instructional and regulative discourses are made explicit (Bernstein, 2000), is undermined by my argument in this paper for an alternative interpretation of "visible pedagogy" that embraces a socially-just pedagogy.

In Section 3, I outlined how equity-minded teachers might move closer towards adopting such a socially-just pedagogy by considering ways of making their pedagogic rationale more explicit to learners. I highlighted the potential for such a pedagogic shift to help students, particularly those from disadvantaged backgrounds, avoid misinterpreting their teacher's actions and develop a greater appreciation of their teacher's pedagogic rationale. In so doing, this approach offers the hope that a wider range of students might identify as mathematics learners and engage more fully with the "rules of the game" that need to be followed in order to gain success in school mathematics.

In Section 4, I drew on my extensive experience of observing lessons to offer a vignette of typical classroom practice. In analysing this vignette in relation to three sociocultural frameworks, I exemplified what making the teacher's pedagogic rationale more explicit to learners might look like in practice. As well as highlighting what teachers might do differently, I outlined the support that might be provided by teacher educators (such as myself) to encourage teachers to reflect critically on their existing practice, assumptions and beliefs relating to mathematics teaching and learning. A greater appreciation of the disempowering and iniquitous nature of teacher-centred pedagogies should be developed through facilitating teachers' engagement with sociocultural frameworks, such as those discussed in Section 3. This would require teacher educators to integrate these frameworks into the ITE curriculum and use them as a basis for facilitating critically-reflective discussions of student teachers' classroom 
practice. Those agencies responsible for advancing mathematics-specific continuing professional development (including the National Centre for Excellence in the Teaching of Mathematics and the Maths Hubs in England) should ensure that teachers are provided with opportunities to engage in similar critically-reflective discussions on an ongoing basis. Encouraging teachers to explore ways of sharing their pedagogic rationale with students offers the potential to support them in developing a more carefully-thought-through and coherent pedagogic rationale for their own practice, informed by sociocultural theories.

An important question to consider is whether it is possible to go too far in making the teacher's pedagogic rationale more explicit to learners. Adler (1999) highlights "the dilemma of transparency" which became apparent in a study she carried out of explicit mathematics language teaching in South Africa. She describes how, when teachers focused explicitly on the development of the mathematical language needed to communicate reasoning, it was possible for students to lose sight of the mathematical concepts being studied. She relates this to Lave and Wenger's (1991, cited in Adler, 1999) notion of "mediating technologies", which need to be simultaneously visible (so that they are noticed) and invisible (so that attention is not diverted from the subject matter). The solution I would argue is to seek an appropriate balance between focusing teaching on developing these mediating technologies and using them as tools to engage with the subject matter more effectively. This means choosing carefully times when it would be most beneficial to focus teaching on cultivating students' awareness of the teacher's pedagogic rationale (i.e. only some of the time). A similar argument could be made for the use of formative assessment and metacognition.

The problematic nature of dominant forms of mathematics pedagogy, highlighted earlier in this section, demands that the refined conceptualisation of socially-just pedagogy I propose in this paper be given further consideration. Bernstein (2000) highlights how competence models of teaching generally require higher levels of teaching experience, pedagogical expertise and knowledge than more teacher-centred approaches. This is compounded by teachers' dispositions towards adopting the same teaching approaches they experienced themselves as learners, given the success they experienced in school (Bourdieu \& Passeron, 1990). Exploring ways of making their pedagogic rationale more explicit to learners is therefore likely to place additional demands on teachers and will require significant support from others. Given the need to challenge existing practice and dominant modes of teaching in school mathematics, research needs to be carried out into ways of encouraging teachers to reflect critically on their own practice in relation to research findings, to question the legitimacy of commonly-held beliefs and assumptions about teaching and learning mathematics, and to try out and evaluate new ideas in their classrooms over a prolonged period of time (Jaworski, 2006; Kemmis, 2009; Liu, 2015). Developing such a model of professional development, along with strategies for making the rationale for sociallyjust pedagogies more explicit to mathematics learners, is the focus of the Visible Maths Pedagogy Research Project, which I am currently working on collaboratively with two teacher researchers, Tiago Carvalho and Alba Fejzo, from Stoke Newington School in London (Wright, 2019). We have published our initial findings from the project (Wright, Fejzo, \& Carvalho, 2020) and hope to publish further findings in the coming months. 


\section{Acknowledgements:}

I am grateful to colleagues at UCL Institute of Education for their valuable feedback on a draft version of this paper I shared with them at a meeting of the mathematics education special interest group and to the reviewers for their helpful comments on my initial submissions.

\section{References:}

Adler, J. (1999). The dilemma of transparency: Seeing and seeing through talk in the mathematics classroom. Journal of Research in Mathematics Education, 30(1), 47-64.

Bennett, R. (2011). Formative assessment: A critical review. Assessment in Education: Principles, Policy \& Practice, 18(1), 5-25.

Bernstein, B. (2000). Pedagogy, symbolic control and identity: Theory, research, critique (Revised ed.). Lanham, Maryland: Rowman \& Littlefield Publishers.

Black, L., Mendick, H., \& Solomon, Y. (2009). Mathematical relationships in education: Identities and participation. New York: Routledge.

Black, P., \& Wiliam, D. (1998). Inside the black box: Raising standards through classroom assessment. London: Kings College London.

Boaler, J. (1998). Open and closed mathematics: Student experiences and understandings. Journal for Research in Mathematics Education, 29(1), 41-62.

Boaler, J. (2008). Promoting 'relational equity' and high mathematics achievement through an innovative mixed-ability approach. British Educational Research Journal, 34(2), 167-194.

Boaler, J., Altendorf, L., \& Kent, G. (2011). Mathematics and science inequalities in the United Kingdom: When elitism, sexism and culture collide. Oxford Review of Education, 37(4), 457-484.

Bourdieu, P., \& Passeron, J.-C. (1990). Reproduction in education, society and culture (2nd ed.). London: Sage.

Brousseau, G. (1984). The crucial role of the didactical contract in the analysis and construction of situations in teaching and learning mathematics. In H. Steiner, Theory of mathematics education (pp. 110-119). Bielefeld: Institut fur Didaktik der Mathematik der Universitat Bielefeld.

Brousseau, G. (1997). Theory of didactical situations in mathematics 1970-1990. Dordrecht: Kluwer.

Chevallard, Y. (2007). Readjusting didactics to a changing epistemology. European Educational Research Journal, 6(2), 131-134.

Cockcroft, W. (1982). Mathematics Counts: Report of the Committee of Inquiry into the Teaching of Mathematics in Schools. London: Her Majesty's Stationery Office.

Cotton, T. (2013). Towards a mathematics for human rights and social justice. In A. Coles, R. Barwell, T. Cotton, J. Winter, \& L. Brown (Eds.), Teaching secondary mathematics as if the planet matters (pp. 73-83). Abingdon: Routledge.

Department for Education (2019). ITT Core Content Framework. London: DfE.

Ewing, B. (2011). Direct Instruction in mathematics: Issues for schools with high indigenous enrolments: A literature review. Australian Journal of Teacher Education, 36(5), 65-92.

Foster, C. (2013). Resisting reductionism in mathematics pedagogy. The Curriculum Journal, 24(4), 565-585. 
Foster, C. (2018). Developing mathematical fluency: Comparing exercises and rich tasks. Educational Studies in Mathematics, 97(2), 121-141.

Grootenboer, P. (2013). The praxis of mathematics teaching: Developing mathematical identities. Pedagogy, Culture and Society, 21(2), 321-342.

Gutstein, E. (2006). Reading and writing the world with mathematics: Toward a pedagogy for social justice. New York: Routledge.

Hattie, J. (2009). Visible learning: A synthesis of over 800 meta-analyses relating to achievement. London: Routledge.

Hodgen, J., \& Marks, R. (2009). Mathematical 'ability' and identity: A sociocultural perspective on assessment and selection. In L. Black, H. Mendick, \& S. Solomon (Eds.), Mathematical relationships in education: Identities and participation (pp. 31-42). New York: Routledge.

Hodgen, J., Foster, C., Marks, R., \& Brown, M. (2017). Improving mathematics in Key Stages Two and Three: Guidance report. London: Education Endowment Fund.

Hudson, B. (2018). Powerful knowledge and epistemic quality in school mathematics. London Review of Education, 16(3), 384-397.

Jaworski, B. (2006). Theory and practice in mathematics teaching development: Critical inquiry as a mode of learning in teaching. Journal of Mathematics Teacher Education, 9(2), 187-211.

Jorgensen, R. (2016). The elephant in the room: Equity, social class, and mathematics. In P. Ernest, B. Sriraman, \& N. Ernest (Eds.), Critical mathematics education: Theory, practice and reality (pp. 127-146). Charlotte, NC: Information Age Publishing.

Jorgensen, R., Gates, P., \& Roper, V. (2014). Structural exclusion through school mathematics: Using Bourdieu to understand mathematics as a social practice. Educational Studies in Mathematics, 87, 221-239.

Kemmis, S. (2009). Action research as a practice-based practice. Educational Action Research, 17(3), 463-474.

Lincoln, Y. S., \& Guba, E. G. (2003). Paradigmatic controversies, contradictions, and emerging confluences. In N. K. Denzin, \& Y. S. Lincoln (Eds.), The landscape of qualitative research: Theories and issues (pp. 253-291). Thousand Oaks, CA: Sage.

Liu, K. (2015). Critical reflection as a framework for transformative learning in teacher education. Educational review, 67(2), 135-157.

Lubienski, S. T. (2004). Decoding mathematics instruction: A critical examination of an invisible pedagogy. In J. Muller, B. Davies, \& A. Morais, Reading Bernstein, researching Bernstein (pp. 91-122). London: Routledge.

Marshall, B., \& Drummond, M. (2006). How teachers engage with Assessment for Learning: Lessons from the classroom. Research papers in education, 21(2), 133-149.

Mason, J. (2002). Researching your own practice: The discipline of noticing. London: Routledge.

Morgan, C. (2009a). Questioning the mathematics curriculum: a discursive approach. In L. Black, H. Mendick, \& Y. Solomon (Eds.), Mathematical relationships in education: Identities and participation (pp. 97-106). New York: Routledge. 
Morgan, C. (2009b). Understanding practices in mathematics education: Structure and text. Psychology of Mathematics Education (pp. 49-64). Thessaloniki: International group for the Psychology of Mathematics Education.

Nardi, E., \& Steward, S. (2003). Is mathematics T.I.R.E.D.? A profile of quiet disaffection in the secondary mathematics classroom. British Educational Research Journal, 29(3), 345-367.

OFSTED. (2012). Mathematics: made to measure. Manchester: The Office for Standards in Education, Children's Services and Skills.

Pepin, B. (2014). Using the construct of the Didactic Contract to understand student transition into university mathematics education. Policy Futures in Education, 12(5), 646-657.

Schoenfeld, A. (2012). Problematizing the didactic triangle. ZDM Mathematics Education, 44(5), 587-599.

Skemp, R. (1972). The psychology of learning mathematics. London: Penguin.

Skovsmose, O. (2011). An invitation to critical mathematics education. Rotterdam: Sense Publishers.

Smith, J., \& Mancy, R. (2018). Exploring the relationship between metacognitive and collaborative talk during group mathematical problem-solving - what do we mean by collaborative metacognition? Research in Mathematics Education, 20(1), 14-36.

Smith, J., Lee, V., \& Newmann, F. (2001). Intruction and achievement in Chicago schools. Chicago: Consortium on Chicago School Research.

Straehler-Pohl, H., \& Gellert, U. (2013). Towards a Bernsteinian language of description for mathematics classroom discourse. British Journal of Sociology of Education, 34(3), 313-332.

Swan, M. (2006). Collaborative learning in mathematics: A challenge to our beliefs and practices. Leicester: National Institute of Adult Continuing Education.

Valero, P. (2004). Socio-political perspectives on mathematics education. In P. Valero, \& R. Zevenbergen (Eds.), Researching the socio-political dimensions of mathematics education (pp. 5-23). Dordrecht: Kluwer Academic Publishers.

Vorholter, K. (2019). Enhancing metacognitive group strategies for modelling. ZDM, 51, 703-716.

Williams, J., \& Choudhury, S. (2016). Mathematics capital in the educational field: Beyond Bourdieu. Research in Mathematics Education, 18(1), 3-21.

Wright, P. (2016). Social justice in the mathematics classroom. London Review of Education, 14(2), 104-118.

Wright, P. (2017). Critical relationships between teachers and learners of school mathematics. Pedagogy, Culture and Society, 25(4), 515-530.

Wright, P. (2019). Visible pedagogy and challenging inequity is school mathematics. Proceedings of the Eleventh Congress of the European Society for Research in Mathematics Education (CERME 11). Utrecht: European Society for Research in Mathematics Education.

Wright, P., Fejzo, A., \& Carvalho, T. (2020). Challenging inequity in mathematics education by making pedagogy more visible to learners. International Journal of Mathematical Education in Science and Technology, DOI: 10.1080/0020739X.2020.1775320. 